NBER WORKING PAPER SERIES

\title{
NATIONAL CULTURES AND SOCCER VIOLENCE
}

\author{
Edward Miguel \\ Sebastián M. Saiegh \\ Shanker Satyanath \\ Working Paper 13968 \\ http://www.nber.org/papers/w13968
NATIONAL BUREAU OF ECONOMIC RESEARCH
1050 Massachusetts Avenue
Cambridge, MA 02138
April 2008

Corresponding author: Edward Miguel, 508-1 Evans Hall \#3880, University of California, Berkeley CA 94720-3880. We are grateful to Dan Altman, Ray Fisman, Matias Iaryczower, David Laitin, Dani Rodrik, and a host of anonymous bloggers for useful comments, and Dan Hartley, Teferi Mergo, and Melanie Wasserman for excellent research assistance. All errors remain our own. The views expressed herein are those of the author(s) and do not necessarily reflect the views of the National Bureau of Economic Research.

NBER working papers are circulated for discussion and comment purposes. They have not been peerreviewed or been subject to the review by the NBER Board of Directors that accompanies official NBER publications.

(C) 2008 by Edward Miguel, Sebastián M. Saiegh, and Shanker Satyanath. All rights reserved. Short sections of text, not to exceed two paragraphs, may be quoted without explicit permission provided that full credit, including $(\mathrm{C}$ notice, is given to the source. 
National Cultures and Soccer Violence

Edward Miguel, Sebastián M. Saiegh, and Shanker Satyanath

NBER Working Paper No. 13968

March 2008

JEL No. K0,O57,Z1

\begin{abstract}
$\underline{\text { ABSTRACT }}$
Can some acts of violence be explained by a society's "culture"? Scholars have found it hard to empirically disentangle the effects of culture, legal institutions, and poverty in driving violence. We address this problem by exploiting a natural experiment offered by the presence of thousands of international soccer (football) players in the European professional leagues. We find a strong relationship between the history of civil conflict in a player's home country and his propensity to behave violently on the soccer field, as measured by yellow and red cards. This link is robust to region fixed effects, country characteristics (e.g., rule of law, per capita income), player characteristics (e.g., age, field position, quality), outliers, and team fixed effects. Reinforcing our claim that we isolate cultures of violence rather than simple rule-breaking or something else entirely, there is no meaningful correlation between a player's home country civil war history and soccer performance measures not closely related to violent conduct.
\end{abstract}

Edward Miguel

Department of Economics

508-1 Evans Hall \#3880

Berkeley, CA 94705-3880

and NBER

emiguel@econ.berkeley.edu

Sebastián M. Saiegh

Department of Political Science, Social Sciences B

9500 Gilman Drive

La Jolla, CA 92093

ssaiegh@ucsd.edu
Shanker Satyanath

NYU Department of Politics

19 W. 4th Street

New York, NY 10012

ss284@nyu.edu 


\section{Introduction}

Researchers increasingly acknowledge the adverse effects of violence on economic development, but the causes of violence remain imperfectly understood (Heinemann and Verner 2006, Murdoch and Sandler 2004, World Bank 2003). Our understanding of the role of social and cultural norms in driving violence is especially limited, due to inherent empirical challenges. Conventional efforts to control for non-cultural factors in a regression framework are complicated by the fact that both formal legal and informal cultural restraints on violent conduct reinforce each other and are thus plausibly correlated across societies (for an example see Waldmann 2007: 63). Inferences about national culture drawn from cross-country comparisons of the incidence of violent acts, such as violent crime rates, are also unsatisfying because laws and income levels (two plausible alternative explanations) differ across societies and may interact with culture in complicated ways (Becker 1968). Moreover, limited cross-national coverage of crime data (especially for less developed countries), and differences in crime reporting standards, make it difficult to draw clear inferences about the presence of violent national cultures using available crime statistics.

This short paper implements a novel research strategy to establish the empirical importance of cultures of violence. We study violence on the soccer (football) field in the European soccer leagues, a cosmopolitan environment where thousands of individuals from numerous countries regularly choose whether or not to use violence to achieve their aims. The European soccer leagues offer a natural experiment for our purposes because they constitute a setting where individuals from different countries make these decisions in a common legal institutional setting, and where we can also effectively control for alternative explanations for violence. Our focus is on the relationship between a country's history of civil war and violence on the soccer pitch. The strong link between war and norms of violent conduct described by sociologists (see below), combined with reliable civil war data across a wide cross-section of countries, allow us to rigorously explore this relationship. 
Our main empirical measures of individual violent conduct are the number of yellow and red cards earned. According to soccer's official rules, players who commit exceptionally violent fouls warrant a disciplinary sanction in the form of a caution (indicated by a yellow card) or a dismissal from the match (indicated by a red card). Using data from six of the world's major soccer leagues (all in Europe), containing players from all continents and seventy countries, we obtain a striking empirical pattern: a strong correlation between the history of civil war in a player's native country and his likelihood of earning yellow and red cards. Confirming that civil war history captures an aspect of culture related to violent acts, rather than general rule-breaking or something else entirely, there is no meaningful relationship between home country conflict and other soccer performance measures that are not closely related to violent conduct.

This main result is robust to extensive controls for player characteristics, country income levels and continent fixed effects, where we effectively compare nearby countries (for example, African countries with different civil war histories). Beyond providing a novel real-world measure of individuals’ willingness to commit acts of violence, this finding indicates that some aspects of national culture are persistent even when individuals are far from home in a different institutional setting, here, a professional sports league. Below, we discuss other robustness checks and the issue of player selection into our sample.

Other studies have used the sports playing field as a laboratory for studying individual decision-making under a clear set of common rules - e.g., Smith (1979a, 1979b), Weinstein et al. (1995), Chiappori, Levitt and Groseclose (2002), Duggan and Levitt (2002), Levitt (2002), Milanovic (2005), Witt (2005), Garicano and Palacios-Huerta (2006), and Price and Wolfers (2007) - but to our knowledge we are the first to use sports to explore cross-country cultural norms regarding violence. This paper also relates to a growing literature relying on culture to explain important economic phenomena, for example Guiso et al. (2006), Bisin and Verdier (2000), Spolaore and Wacziarg 
(2006), Fernandez and Fogli (2005), and Tabellini (2005), although these papers do not specifically examine cultures of violence. Fisman and Miguel (2008) exploit the stationing of diplomats at the United Nations in New York to explore the persistence of corruption norms.

The next section describes estimation and data, following by the results, and the conclusion.

\section{Data and Estimation}

This paper analyses the behavior of soccer players to create a revealed preference measure of individuals' cultural proclivity to engage in violent conduct. As mentioned, actual crime rates are unsatisfactory as measures of a "culture of violence”, since individuals' real-world actions plausibly reflect the combined influence of legal institutions and economic factors, in addition to cultural norms. We argue that the European soccer leagues offer a setting where individual behavior can be studied within a common institutional backdrop, and where we can effectively control for alternative explanations for violence, allowing us to isolate the effect of persistent cultural norms alone.

Soccer's official rules, the so-called "Laws of the Game," are provided centrally by the Fédération Internationale de Football Association (FIFA), the international governing body. ${ }^{1}$ Every soccer game has one referee with the authority to apply disciplinary sanctions, and the rules establish clear penalties for different types of fouls, misconduct, and aggressive behavior. Most fouls are minor and occur within the natural flow of the game's action; these fouls do not earn the player any additional punishment. In contrast, when a more serious offense is committed, the rules stipulate a disciplinary sanction, in particular a caution or dismissal. A caution earns the player a "yellow card." In these cases, the referee stops the match, calls the player over, holds up the yellow card, and writes the player's name in his notebook. A player who receives a yellow card continues to play in the match, yet the yellow card serves as the first and last formal warning.

\footnotetext{
${ }^{1}$ See http://www.fifa.com/mm/document/affederation/federation/lotg2006_e_1581.pdf. Referees have incentives to closely adhere to the guidelines: those not enforcing the rules may be assigned to minor games, or dismissed.
} 
We define violent conduct as behavior that either deliberately risks inflicting injury on an opponent, or that is so excessively aggressive that it carries the potential of provoking a violent response. ${ }^{2}$ Soccer yellow cards are usually granted for excessively violent fouls, but may also be awarded for swearing at an opponent; humiliating the opponent after scoring a goal (with excessive celebration); or “diving” to falsely pin a foul on an opponent. Soccer yellow cards thus effectively capture our notion of violent conduct.

In this paper, we also examine red card fouls as a measure of an even greater degree of violent conduct. A second yellow card in the same match leads to a red card dismissal, and in cases of egregious behavior a red card may be assigned without the yellow card warning. ${ }^{3}$ When a player is expelled, no replacement is permitted, so his team must complete the match short one player. In one league where data are available, $40 \%$ of red cards were directly awarded for exceptionally violent fouls (“assault”), 19\% for “professional fouls” (a deliberate act of foul play, usually to prevent an opponent scoring and sometimes violent), with the rest for “other unsporting acts”.

Our dataset contains information from the 2004/2005 and 2005/2006 soccer seasons in five national leagues (England, France, Germany, Italy, Spain) and one supra-national league (the UEFA Champions League), from publicly available websites. ${ }^{5}$ We also have data on each individual player's quality as measured by his market value. We obtained this information from a soccer management simulation video game; the game features real players and real teams, including each player's transfer fees and salary. ${ }^{6}$

\footnotetext{
${ }^{2}$ Note that real-world wars could result from either mechanism (direct attack or provocation).

${ }^{3}$ Beyond expulsion from the current match, a red card often leads to a suspension from future matches; players who accumulate multiple yellow cards in different matches in the same season may also receive later suspensions.

${ }^{4}$ Source: UEFA Disciplinary Statistics 2003/2004, page 6: http://www.uefa.com/newsfiles/249438.pdf. The figures above exclude "second yellow cards", since the underlying behavior that caused these yellow cards is not reported.

${ }^{5}$ The data was downloaded from the ESPN Soccernet site (using a Perl script): soccernet.espn.go.com/.

${ }^{6}$ The game is called Worldwide Soccer Manager in the U.S. and Football Manager elsewhere. We use the 2005 and 2006 releases. The game was developed by Sports Interactive, and the database is assembled by 2500 researchers worldwide. We searched for news stories regarding prominent players' transfer fees to confirm reliability.
} 
Our sample contains several of the world's most high-profile soccer leagues and a remarkably international collection of players, drawn to Europe by the world's highest player salaries (Dobson and Goddard 2001). The mean annual salary in our sample amounts to US\$1,291,517, and the average player is worth US\$ 6,323,515 (see Table 1). The main analysis sample includes 5,035 player-year observations for players from 70 different countries (see the appendix table). To ensure at least a moderate amount of information per country, we only consider countries with five or more player-seasons represented in our sample, though results are nearly identical using other thresholds.

There are many more yellow cards (mean 2.43 per player per season, see Table 1 ) reported than red cards (mean 0.15 cards), and in practice we focus most analysis on yellow cards. ${ }^{7}$ We have information on players' citizenship as well as on-field statistics (field position, games played, goals scored, yellow and red cards). While most players in the European leagues are from wealthy OECD countries (mainly within Europe), large fractions are from Africa, Eastern Europe, and Latin America, with smaller numbers of Asians (Table 1).

To determine the nationality of those players who hold dual citizenship, we focus on their participation on a national team rather than birthplace. Many players originally from less developed countries play for European national teams, and if anything, using this criterion plausibly leads us to underestimate the effect of home country civil war history on violent soccer conduct. The bestknown illustration is French star Zinedine Zidane. Even before his headbutt in the 2006 World Cup Final earned him a red card, Zidane was well-known for his violence on the pitch and had received fourteen red cards throughout his career. Though Zidane holds dual French and Algerian citizenship, he chose to play for the French national team and so under our coding rules is French (a country with no civil war during 1980-2005) rather than Algerian (15 civil war years during the same period).

We control for many of the soccer-related factors correlated with fouls and violence on the field, the most important being the player's field position - defenders and midfielders generally

\footnotetext{
${ }^{7}$ These figures are consistent with Witt (2005) and Garicano and Palacios-Huerta (2006).
} 
commit more fouls than forwards, who in turn commit more than goalkeepers - as well as the number of games played as a starter or substitute. A player's age may also correlate with fouls and so is included as a further control. We also control for players' quality using two different indicators. The first one is his success as a goal scorer, measured by the number of goals scored. The second is a player's worth, as measured by his transfer fee (which is highly correlated with his salary).

We include league fixed effects to address any differences in the calling of cards or fouls across countries, and team fixed effects (in some specifications) to capture differences in team quality or playing style and tactics, as these represent a further possible source of variation in the incidence of yellow/red cards. The fact that referees have some discretion in calling fouls and awarding cards raises the possibility of bias, and one leading concern is discrimination against players of particular racial or ethnic backgrounds. ${ }^{8}$ To control for such bias, we include world region fixed effects - for Africa, Asia, Latin America, and Eastern Europe - in all specifications. These terms also capture any other factors, including regional styles of play (“dirty” or “clean”) or region-wide cultures of violence, allowing us to isolate variation across countries within the same region.

Our analysis focuses on the correlation between violent individual conduct on the soccer field and the history of civil war in the player's home country. Specifically, we employ the number of years a country suffered from civil war between 1980 and 2005 using the popular PRIO/Uppsala Armed Conflict Dataset. ${ }^{9}$ Following their conflict classification, we include both "internal armed conflicts" and "internationalized internal armed conflicts", using the comprehensive 25 battle death annual threshold. The former are defined as “conflicts that occur between the government of a state and one or more internal opposition group(s) without intervention from other states”, while the latter

\footnotetext{
${ }^{8}$ This is not an idle concern: there is evidence of racial bias among U.S. National Basketball Association referees (see Price and Wolfers 2007).

${ }^{9}$ We focus on the 1980-2005 period because it corresponds closely with the age of the players included in our sample. The results are robust when we look at longer periods, including 1960-2005 (see below).
} 
occur "with intervention from other states (secondary parties) on one or both sides." ${ }^{10}$ We use this indicator rather than using other measures of violent crime (such as murders per capita) for two reasons. First, even the most extensive (to our knowledge) source of cross-national statistics on crime data, the United Nations Survey of Crime Trends and Operations of Criminal Justice Systems, has limited country coverage. Second, as per their own disclaimer, their statistics are "better indicators of prevalence of law enforcement and willingness to report crime, than actual prevalence.”11

We believe that there are good conceptual reasons to expect a strong correlation between home country civil conflict history and subsequent violent conduct. Sociologists have found that war-time killing has a major impact on national social norms and values, fostering greater tolerance for violent behavior postwar (see Archer and Gartner 1976, Steenkamp 2005, 253-54). War’s lingering effects are "clearly associated with more homicide and assault, in the ethnographic record as well as cross nationally” (Ember and Ember 1994, 622; see also Heinemann and Verner 2006). In other words, a history of violence appears to change norms and local “culture”, making violent conduct more socially acceptable, expected, or even desirable.

Soccer is an intrinsically physical game, where the use of strength may play an important role. However, it is usually associated with physical stamina, the ability to push the body to its limits in an attempt to win, and retain, possession of the ball, rather than with violence. The main distinction is between playing "hard” and playing “dirty.” The view of what constitutes acceptable behavior, though, may vary across cultures. As Archetti and Romero (1994) point out, in those countries where it is considered a national sport, soccer not only reflects social and cultural processes but it is a part of those very same processes. In their words, "football is an arena in which social actors symbolize and reproduce by means of their social practices the values dominant in a given

\footnotetext{
${ }^{10}$ See www.prio.no/cwp/ArmedConflict/ for details on the dataset. No extra-systemic armed conflicts occurred during 1980-2005 and thus they are not included in our sample. The results are if anything somewhat stronger when we exclude the small number of internationalized conflicts (not shown).

${ }^{11}$ For countries with crime data, see www.unodc.org/unodc/en/data-and-analysis/Crime-Monitoring-Surveys.html.
} 
period” (p. 39), and thus players from different cultures may tolerate different degrees of violence on the soccer field. The main implication for our study is that the interaction of players from different countries under the same "institutional environment" will reveal these different cultural norms.

An alternative link between national culture and violence is equally plausible, namely, that those societies with a greater underlying tolerance of violent behavior are also those most likely to suffer from protracted civil conflicts. In this case, it is the culture of violence that drives civil war, rather than the other way around. We do not take a stand on which of these two causal mechanisms is correct, nor do we need to in the current analysis: either way, the extent of civil war in a nation's past reflects the social legitimization of violence, which we seek to correlate with on-field play.

Note that our goal in this paper is to capture the specific effects of violent cultures, as opposed to other cultural dimensions, for instance respect for the rule of law. To capture players' “cultural” propensity to respect rules more broadly, we also control for the degree of rule of law in the home country using the Worldwide Governance Indicators (WGI) project dataset. ${ }^{12}$

A count model analysis is appropriate for our analysis given the nature of the dependent variables, the total number of offenses (yellow card fouls, red card fouls, regular no-card fouls, and goals) by player-season. We focus on the negative binomial model (the Poisson model is rejected at high levels of confidence). ${ }^{13}$ Standard errors are robustly estimated and the disturbance terms for each country are allowed to be correlated.

Our sample of professional soccer players is obviously highly selected. These players are all young men with exceptional physical ability, and thus may not be representative of their home country's population in terms of their proclivity to engage in violent conduct. In other words, external validity is a potential concern: women from these countries, or people at different ages or with worse health status, etc., could behave differently. That said, the fact that the selection rule is

\footnotetext{
${ }^{12}$ These data are available at: http://www.govindicators.org. Summary statistics are presented in Table 1.

${ }^{13}$ We actually do not find over-dispersion for red cards, but negative binomial model results are virtually identical to those generated by Poisson. For consistency, we report negative binomial results for all dependent variables.
} 
uniform across countries - the representatives of each nation in our sample are young men with exceptional athletic talent - alleviates concerns about internal validity. Besides, the fact that physically robust young men are the main perpetrators of violence in nearly all societies today (and historically) makes this a population of exceptional interest for the study of violence.

\section{Empirical Results}

The number of yellow cards earned is positively associated with players' home country civil conflict history at the $99 \%$ confidence level (Table 2, regression 1). The home country history of violence apparently has a powerful association with violent conduct on the soccer field.

A reasonable way to judge the substantive magnitude is to compare it to the effects of soccer related determinants of yellow cards, such as age. The nonlinear nature of our estimator means there is no single marginal effect of a worse civil war history, so we focus on particular subpopulations beginning with players from Africa, where civil war risk is highest. In particular, we consider an African midfielder in the French League (the league with the greatest number of Africans) and set civil war risk and other variables to the African average. The predicted number of yellow cards for such a player increases by 3.6 percent when civil conflict prevalence in his home country increases by one standard deviation, or 4 years. Player age is also positively correlated with yellow cards and can serve as a basis for comparison. If the age of the representative African player decreases by two years, his estimated number of yellow cards decreases by 3.0 percent, roughly offsetting the positive conflict effect. A similar calculation for a representative Latin American playing in the Spanish League (the league with the most Latin Americans) also yields a predicted 3.6 percent increase in yellow cards when civil war increases by one standard deviation.

Figure 1 presents a scatter-plot relating years of civil war for each country between 1980 and 2005 (on the horizontal axis) to the average number of yellow cards earned per player-season, both conditional on the control variables included in Table 2, regression 1; the area of the country circles 
is drawn proportional to the number of player-seasons of that nationality represented in the sample. The raw graphical relationship is visibly positively sloped. Colombia and Israel are the two sample countries that experienced civil war in every year since 1980, and their players are remarkably violent on the pitch. Inter Milan’s defender Iván Ramiro Córdoba is a case in point: over the 2004-5 and 2005-6 seasons he collected a stunning 25 yellow cards.

This graphical representation raises questions about robustness to excluding countries with long civil war histories (e.g., Colombia, Israel, Turkey, Iran, and Peru), but a series of checks indicate that the main relationship is stable when these seeming outliers are removed. The first test calculates studentized residuals to identify outliers (following Belsley, Kuh, and Welch 1980). When the main model (analogous to Table 2 column 1) is re-estimated omitting outliers, the point estimate on civil war history remains large and statistically significant at 0.0093 (z-score 3.47, not shown). Additional tests excluding each of the five countries with the most civil war years find similar results. The precision of the coefficient estimate on civil war falls most when we exclude Colombian players from the sample, but even in that case the main coefficient estimate is significant at over $90 \%$ confidence (estimate 0.0064 , z-score 1.86); the result remains statistically significant at $90 \%$ confidence when both Colombian and Israeli players are dropped (estimate 0.0059, z-score 1.75, not shown), and this relationship is presented graphically in Figure 2. Finally, including the log of the years of civil war history as the main explanatory variable also yields a statistically significant result at over 95\% confidence (estimate 0.0559 , z-score 2.30, not shown). Taken together these tests indicate that outliers are not driving the main results.

We conducted a similar analysis using a player-specific measure of exposure to violence based on differences in age and the timing of conflict. For each player we recorded the number of years of civil war violence experience by his country until he was eighteen years old. The results that 
we obtained are indistinguishable from the ones we report in Table 2 (not shown). ${ }^{14}$ As an additional robustness check, we also estimated our results including a variable capturing the number of armed conflicts in a country over a longer time period, between 1960 and 2005, and the point estimate remains positive, large, and statistically significant (0.0085, z-score 2.37, not shown).

The main results are virtually identical when regional fixed effects are excluded, and are robust to excluding players from developed countries, where relatively few civil conflicts occur: the coefficient estimate on civil war when OECD players are omitted is even larger at 0.0141 (z-score 4.13, not shown). The relationship between years of civil war and the average number of yellow cards excluding OECD players is presented graphically in Figure 3. The result is robust to the inclusion of country per capita income as an additional control (Table 2, regression 2). ${ }^{15}$ The association between home country civil war history and yellow cards holds conditional on the country rule of law measure (regression 3).

The main finding remains unchanged when we control for team characteristics. The point estimate on the civil war measure is nearly identical at 0.0076 (z-score 2.24, not shown) when team fixed effects are included. The result is also robust to accounting for team quality, measured by their league standings in two variables: the first variable indicates if the team finished among the top five teams in its league, while the second indicates if they finished among the bottom five. Players on top-five teams are less likely to receive yellow cards (coefficient estimate -0.043, z-score 1.68), while players in lowly teams receive more cards (0.063, z-score 1.66$)$, but most importantly, the point estimate on the civil war measure remains large and statistically significant $(0.0072$, z-score 2.48, not shown) when these team controls are included.

\footnotetext{
${ }^{14}$ Results are identical when 21 years of age is the threshold. Results are also unchanged when we control for player salary rather than the transfer fee. Another concern relates to referees' xenophobia (recall that racism is largely controlled with continent fixed effects), but anti-foreigner bias is not driving our results: the estimate on civil war history is unchanged when an indicator for being a foreigner is included (not shown).

${ }^{15}$ The per capita income data (in 2006 PPP U.S. dollars) are from the 2007 World Development Indicators database.
} 
Throughout Table 2 we control for the number of games played as a starter or a substitute, and these variables are likely to be strongly correlated with the amount of time spent on the field, an important determinant of cards. The exact amount of playing time is more difficult to capture since none of the existing data we are aware of - including websites used by fans, professionals, gamblers, and fantasy soccer league participants - reports minutes played. To make sure our results are not being driven by players with minimal playing time, we excluded players who did not participate in at least three games (as either a starter or substitute) in a given season, and find that the coefficient on country civil war history remains large and statistically significant (0.0102, z-score 2.29, not shown).

Two additional yellow card findings are worth noting here. First, there appear to be different playing or refereeing styles across European country leagues. In particular, the specification in Table 2, column one indicates that, relative to the English league, there are many more yellow cards in the French League (0.264, z-score 4.43), the German league (0.318, z-score 6.71), the Italian league (estimate 0.353, z-score 6.51), and especially the Spanish League (point estimate 0.543, z-score 10.88; not shown). Second, the same specification reveals that, ceteris paribus, better-paid players are more likely to receive yellow cards. The explanation for this finding remains elusive, although it is possibly the consequence of high-profile players being targeted for more violent fouls by the opposition and thus provoked into retaliation. In contrast, there are few substantive differences in the proclivity to receive yellow cards across players' home region (Africa versus Latin America, etc.), conditional on the other individual and league controls.

Moving onto other findings, we also studied the effects of civil war history on red cards. This is of interest since many red cards are directly awarded for exceptionally violent fouls, yet it is also a harder test given the low incidence of red cards. We find a large positive effect of home country civil war history on red cards earned, and this effect is statistically significant at over $90 \%$ confidence (Table 2, regression 4). The large positive point estimate - approximately twice as large as that for yellow cards - indicates that civil war history is also highly relevant for explaining this behavior. 
The soccer leagues in our sample compile different information, and only the English, Spanish, and the Champions leagues post complete data on regular (no-card) fouls, reducing our sample size roughly in half. Aside from the decline in sample size, we have an important additional reason for not expecting to find a significant association between civil war history and regular fouls: fouls that do not earn cards are typically less violent than those that do. In fact, referees are called upon in the Laws of the Game to make such a distinction. Regular fouls are an accepted part of soccer, in many circumstances are viewed as a natural way of upsetting the opposing team's flow on the field, and in most cases are committed in a fashion that minimizes the risk of injury to both players. Perhaps not surprisingly, then, in our sample neither civil war history nor the rule of law index are significantly correlated with fouls committed (Table 2, column 5). ${ }^{16}$

As a final specification check, we consider the number of goals scored as the dependent variable, and find no meaningful correlation with civil war history (Table 2, regression 6), indicating that civil war history predicts violence on the soccer pitch but not other aspects of play.

\section{Discussion and Conclusion}

We exploit the natural experiment offered by the presence of thousands of international soccer players all playing within a common institutional environment in the European soccer leagues to identify the presence of cultures of violence. We find that the player's home country's history of violent civil conflict is strongly associated with violent behavior on the soccer pitch, as captured in yellow and red cards, but not other dimensions of play, such as regular (no-card) fouls or goals scored. The leading interpretation is that persistent national cultures of violence accompany these soccer players as they move to Europe. As Michel Platini, the former French star and current UEFA president, put it, soccer players approach the game as “a way of being, a culture” (Kuper 2006).

\footnotetext{
${ }^{16}$ Note that our main finding linking civil war history and yellow cards is robust to using the smaller sample found in Table 2, regression 5 (point estimate 0.0079 , statistically significant at $95 \%$ confidence, not shown).
} 
These findings raise the question of precisely how civil war affects national culture. Our data tentatively suggest that childhood and adolescent exposure to national violence may be the causal channel. We draw this preliminary inference from the fact that the proportion of years before a player reached age 18 that his home country experienced civil war strongly predicts violence on the soccer field (as described above), while civil war history during the 1960s and 1970s, before most of our players were born, does not (not shown). Confirming this channel more rigorously would require extensive survey data of players' attitudes towards violence, and perhaps their personal exposure to violent events, something that is beyond the scope of this study.

If individuals can be socialized into a violent culture, then they could also potentially unlearn their national culture over time if they moved to a different society, yet our data do not offer strong support for this hypothesis. In a variety of specifications not reported above, we tested whether the impact of a player's home country civil war history diminishes over time for older players, or for those with more experience in the European professional leagues, but in no case are these interaction terms statistically significant at traditional confidence levels (not shown). Violent national cultures appear quite persistent, at least over the timeframe of the typical soccer playing career.

We are acutely aware of the need to resist over-interpreting our results. Specifically, the application of results from this admittedly non-representative setting (the soccer field) to broader explanations for wars or violent crime should be done with great caution. Yet to the extent that our results do generalize, and cultures of violence are persistent and qualitatively important, the findings suggest that policymakers need to address cultural factors head-on. Interventions to reduce violent conduct might include conflict resolution or peace-building school curricula in post-war societies, or community projects to alter prevailing norms regarding the use of violence in high-crime neighborhoods. The systematic impact evaluation of programs to modify local culture constitutes a 
promising and novel research avenue for economists studying civil war prone developing countries or high-crime communities within wealthy societies. ${ }^{17}$

\section{References}

Andersen, Thor Einar, Lars Engebresten, and Roland Bahr. 2004. "Rule Violations as a Cause of Injuries in Male Norwegian Professional Football,” American Journal of Sports Medicine, 32: 62-68.

Archer, Dane and Rosemary Gartner. 1976. "Violent Acts and Violent Times: A Comparative Approach to Postwar Homicide Rates,” American Sociological Review ,41 (December):937-63.

Archetti, Eduardo P. and Amilcar G. Romero. 1994. "Death and violence in Argentinean football," in Richard Giulanotti, Norman Bonney, and Mike Hepworth (eds.). Football, Violence, and Social Identity. London: Routledge.

Becker, Gary. 1968. “Crime and Punishment: An Economic Approach,” Journal of Political Economy, 76: 169-217.

Belsley, David A., Edwin Kuh and Roy E. Welch. 1980. Regression Diagnostics. Wiley.

Bisin, Alberto and Thiery Verdier. 2000. "Beyond the Melting Pot: Cultural Transmission, Marriage, and the Evolution of Ethnic and Religious Traits," Quarterly Journal of Economics, 115, 955-88.

Chiappori, P.-A., S. Levitt, and T. Groseclose. 2002. “Testing Mixed-Strategy Equilibria When Players Are Heterogeneous: The Case of Penalty Kicks in Soccer,”American Economic Review, 92 (4), 1138-1151

Collier, Paul, and Pedro C. Vicente. 2008. "Votes and Violence: Experimental Evidence from a Nigerian Election”, unpublished working paper.

Dobson, Stephen and John Goddard. 2001. The Economics of Football. Cambridge University Press.

Duggan M. and Levitt S.D. 2002. "Winning Isn't Everything: Corruption in Sumo Wrestling,” American Economic Review, Volume 92, Number 5: 1594-1605.

Ember, Carol and Melvin. 1994. "War, Socialization, and Interpersonal Violence: A Cross Cultural Study,” Journal of Conflict Resolution, 38 (4): 620-646.

Fernandez, Raquel and Alessandra Fogli. 2005. "Culture: An Empirical Investigation of Beliefs, Work, and Fertility,” NBER Working Paper \#11268.

Fisman, Ray, and Edward Miguel. (2007). "Cultures of Corruption: Evidence from Diplomatic Parking Tickets,” Journal of Political Economy, 115(6), 1020-1048.

Garicano, Luis, and Ignacio Palacios-Huerta. 2006. "Sabotage in Tournaments: Making the Beautiful Game a Bit Less Beautiful,” mimeo, University of Chicago.

\footnotetext{
${ }^{17}$ See Collier and Vicente (2008) for a recent example.
} 
Guiso, Luigi, Paola Sapienza, and Luigi Zingales. 2006. "Does Culture Affect Economic Outcomes?,’’ Journal of Economic Perspectives, 20, 23-48.

Heinemann, Alessandra and Dorte Verner. 2006. "Crime and Violence in Development: A Literature Review of Latin America and the Caribbean,” World Bank Policy Research Working Paper 4041.

Kuper, Simon. 2004. Soccer Against the Enemy. New York: Nation Books.

Levitt, S. D. 2002. “Testing the economic model of crime: the National Hockey League's two-referee experiment,” The Berkeley Electronic Journals in Economic Analysis and Policy, 1: 1-19.

Milanovic, Branco. 2005. “Globalization and goals: does soccer show the way?,” Review of International Political Economy, vol:12 (5)

Murdoch, James and Todd Sandler. 2004. “Civil Wars and Economic Growth: Spatial Dispersion,” American Journal of Political Science 48 (1), 138-151.

Price, Joe and Justin Wolfers, 2007, “Racial Discrimination among NBA Referees”, NBER Working Paper \#13206.

Smith, Michael D. 1979a. "Hockey Violence: A Test of the Violent Subculture Hypothesis," Social Problems, Vol. 27, No. 2: 235-247.

Smith, Michael D. 1979b. "Towards an Explanation of Hockey Violence: A Reference Other Approach,” Canadian Journal of Sociology, Vol. 4, No. 2: 105-124

Spolaore, Enrico and Romain Wacziarg. 2006. “The Diffusion of Development,” NBER Working Paper \#12153.

Steenkamp, Chrissie. 2005. “The Legacy of War: Conceptualizing a 'Culture of Violence’ to Explain Violence after Peace Accords,” The Round Table 94 (April), 253-67.

Tabellini, Guido. 2005. “Culture and Institutions: Economic Development in the Regions of Europe,” CESifo Working Paper \# 1492.

Waldmann, Peter. 2007. “Is There a Culture of Violence in Colombia?,” International Journal of Conflict and Violence, 1 (1), 61-75.

Weinstein, Marc D., Michael D. Smith, and David L. Wiesenthal. 1995. "Masculinity and Hockey Violence,” Sex Roles, Vol 33, Nos. 11/12.

Witt, Robert. 2005. "Do Players React to Sanction Changes? Evidence from the English Premier League,” Scottish Journal of Political Economy, 52: 623-640.

World Bank. 2003. Breaking the Conflict Trap: Civil War and Development Policy. World Bank: Washington, DC. 
Table 1: Descriptive Statistics

\begin{tabular}{|c|c|c|c|c|c|}
\hline Variable & Mean & Std. dev. & Min. & Max. & Obs. \\
\hline \multicolumn{6}{|l|}{ Rule infractions } \\
\hline Yellow cards per player-season & 2.43 & 2.73 & 0 & 16 & 5035 \\
\hline Red cards per player-season & 0.15 & 0.41 & 0 & 3 & 5035 \\
\hline Regular (no-card) fouls per player-season & 13.69 & 16.78 & 0 & 108 & 2660 \\
\hline \multicolumn{6}{|l|}{ Country characteristics } \\
\hline Years of civil war (1980-2005) & 2.74 & 4.74 & 0 & 26 & 5035 \\
\hline Rule of Law (2005-2006) & 0.85 & 0.89 & -1.76 & 2.10 & 5035 \\
\hline GNI per capita (2006) & 26,203 & 10,923 & 720 & 44,260 & 4965 \\
\hline \multicolumn{6}{|l|}{ Player characteristics } \\
\hline Age & 26.0 & 4.40 & 17 & 41 & 5035 \\
\hline Weekly Salary (in '000 USD) & 24.0 & 27.0 & 0 & 190.0 & 5034 \\
\hline Transfer Fee (in ‘000 USD) & $6,323.5$ & $8,189.5$ & 3.0 & $78,000.0$ & 5035 \\
\hline Games Started & 13.80 & 11.48 & 0 & 40 & 5035 \\
\hline Substitute & 3.13 & 3.89 & 0 & 29 & 5035 \\
\hline Goalie & 0.08 & 0.27 & 0 & 1 & 5035 \\
\hline Defender & 0.33 & 0.47 & 0 & 1 & 5035 \\
\hline Forward & 0.23 & 0.42 & 0 & 1 & 5035 \\
\hline Midfield & 0.36 & 0.48 & 0 & 1 & 5035 \\
\hline Goals Scored per player-season & 1.65 & 3.12 & 0 & 31 & 5035 \\
\hline \multicolumn{6}{|l|}{ Player region of origin } \\
\hline Africa & 0.07 & 0.26 & 0 & 1 & 5035 \\
\hline Asia & 0.004 & 0.06 & 0 & 1 & 5035 \\
\hline Latin America/Caribbean & 0.12 & 0.33 & 0 & 1 & 5035 \\
\hline Eastern Europe & 0.07 & 0.25 & 0 & 1 & 5035 \\
\hline OECD & 0.72 & 0.45 & 0 & 1 & 5035 \\
\hline \multicolumn{6}{|l|}{ Soccer leagues } \\
\hline English League & 0.17 & 0.38 & 0 & 1 & 5035 \\
\hline European Champions League & 0.19 & 0.39 & 0 & 1 & 5035 \\
\hline French League & 0.15 & 0.36 & 0 & 1 & 5035 \\
\hline German League & 0.14 & 0.35 & 0 & 1 & 5035 \\
\hline Italian League & 0.17 & 0.38 & 0 & 1 & 5035 \\
\hline Spanish League & 0.16 & 0.37 & 0 & 1 & 5035 \\
\hline
\end{tabular}

Notes: The source of the rule infraction, goals, player characteristics, player country of origin, and soccer leagues data is the ESPN Soccernet website. The source of the civil war data is the PRIO/Uppsala Armed Conflict Database, and the source of the rule of law variable is the Worldwide Governance Indicators (WGI) project. Income per capita is measured in Purchasing Power Parities (2006 dollars); source: World Bank's World Development Indicators (2007). Weekly salaries and transfer fees are expressed in current US Dollars; source: Football Manager 2005, and World Soccer Manager 2006. 
Table 2: Empirical Results

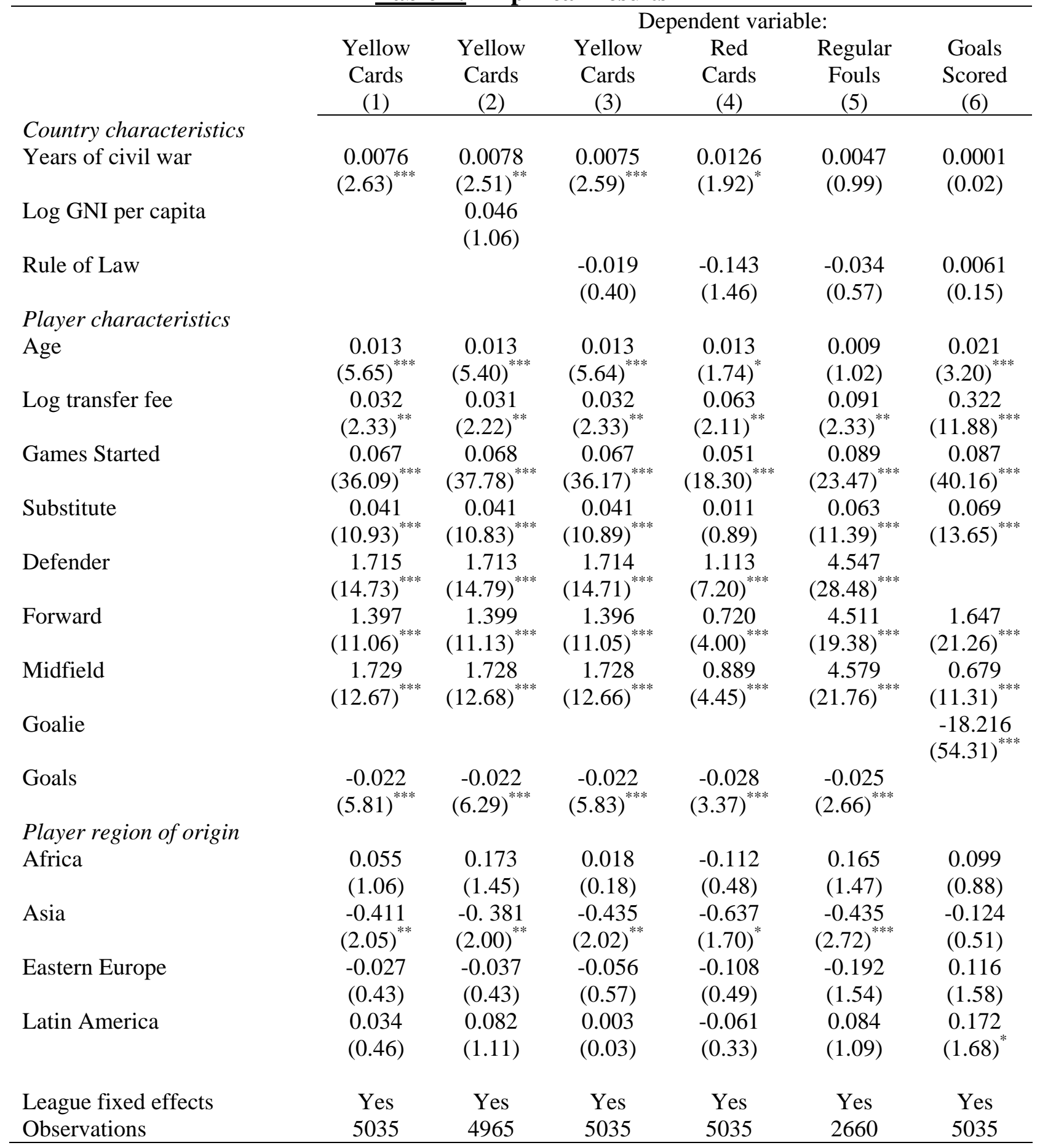

Notes: The dependent variables are per player-season. Columns 1-6 contain the results of negative binomial specifications with disturbance terms clustered at the country level. The omitted categories in columns 1-5 are Goalie (for field position), OECD (for region), and the English Premier League (for league); in column 6, the baseline categories are Defender (for field position), OECD (for region), and the English Premier League (for league). The league fixed effect results are not shown. Z-statistics are in parentheses. Statistical significance at $90 \%(*), 95 \%(* *)$, and $99 \%(* * *)$ confidence levels. 
Figure 1: Yellow Cards and Country Civil War History (conditional on control variables in Table 2, regression 1) - All Countries

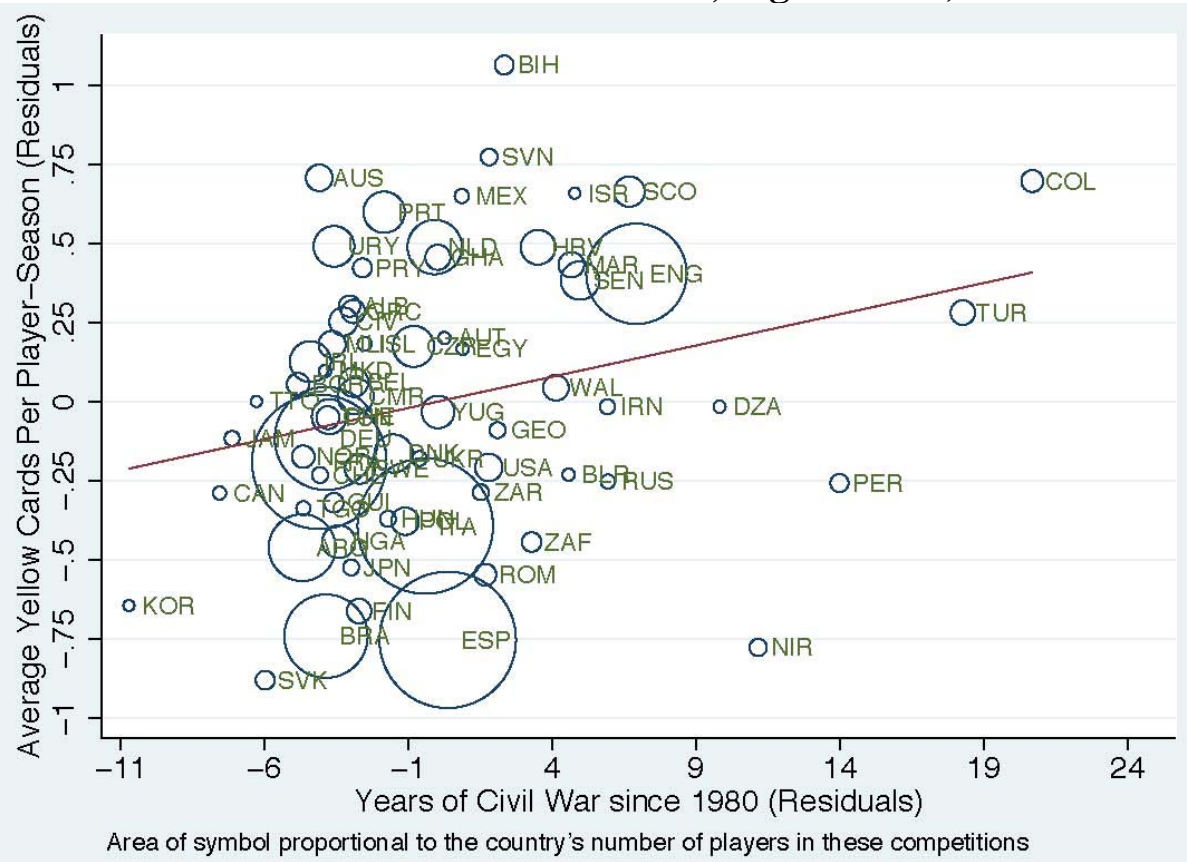

Figure 2: Yellow Cards and Country Civil War History (conditional on control variables in Table 2, regression 1) - excluding Colombia and Israel

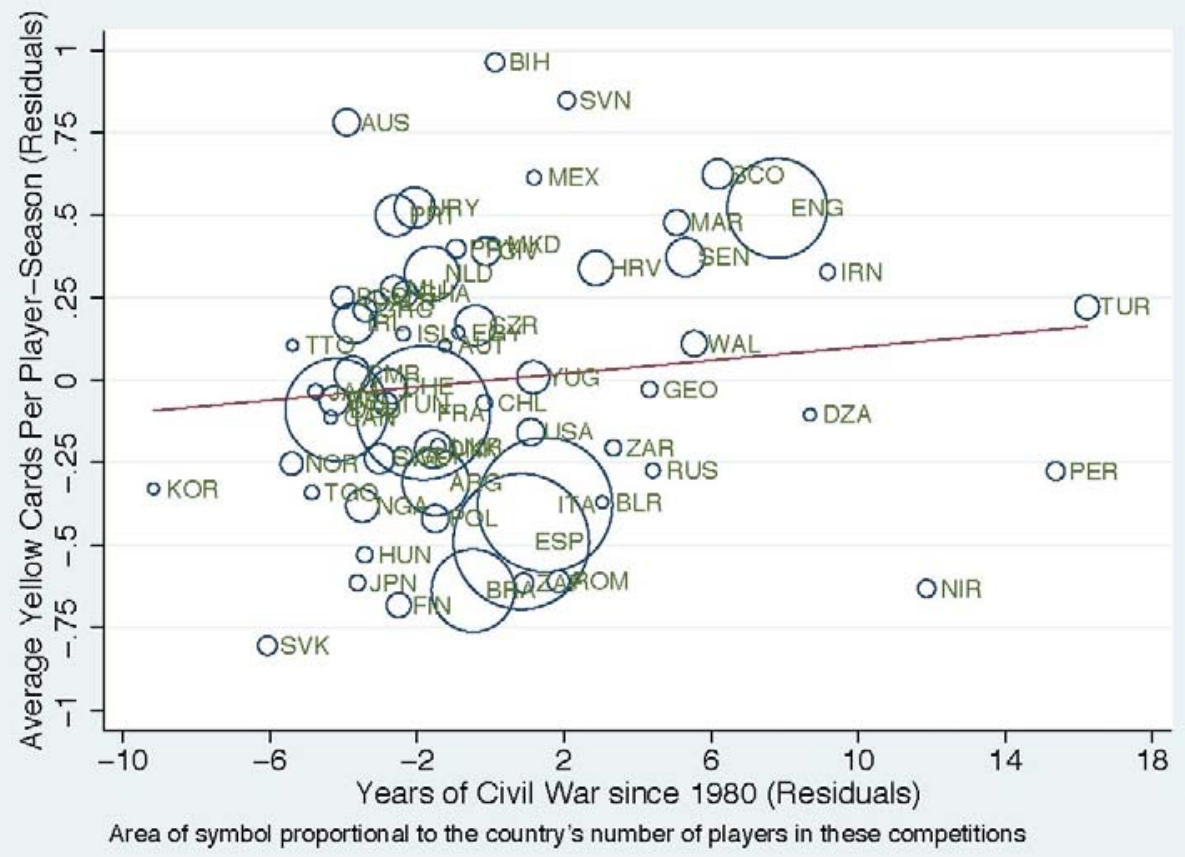


Figure 3: Yellow Cards and Country Civil War History (conditional on control variables in Table 2, regression 1) - Non-OECD Countries

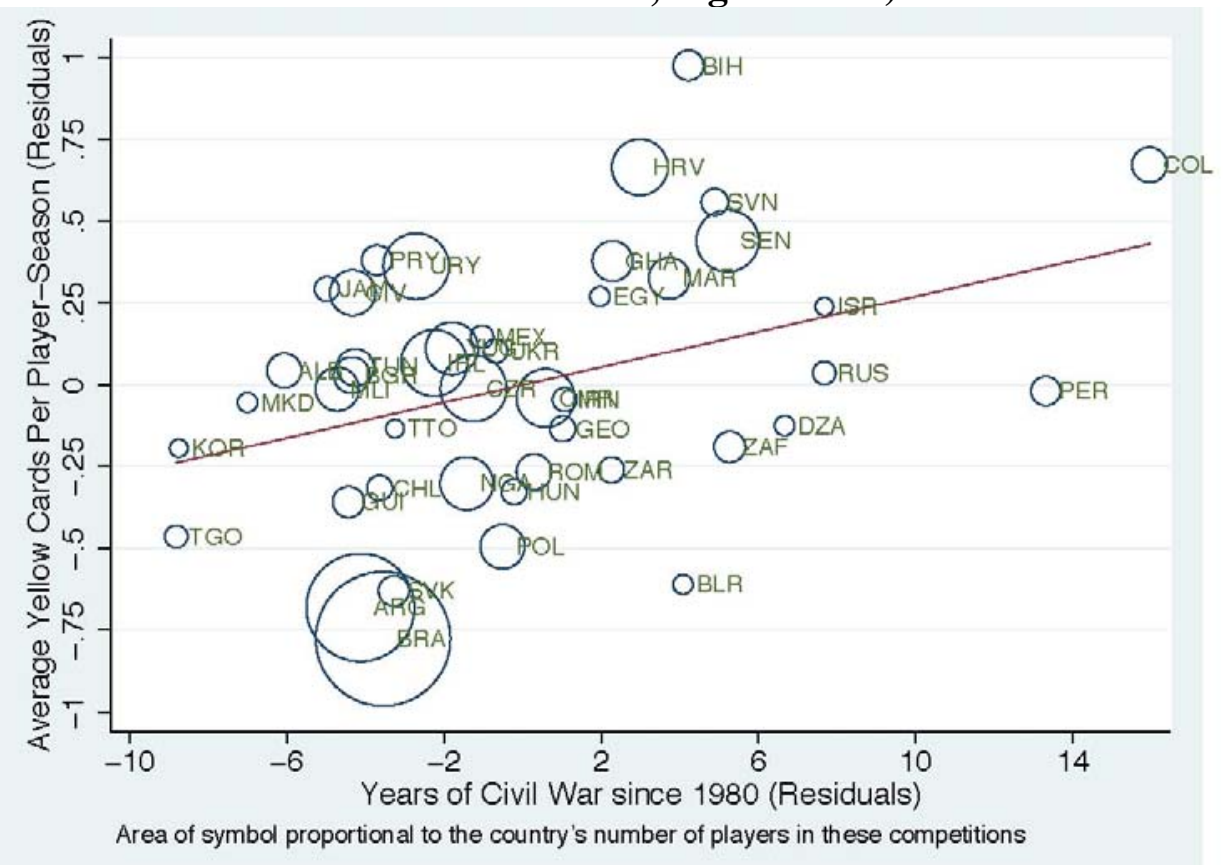


Appendix Table: Countries and Players Represented in the Main Sample

\begin{tabular}{|c|c|c|c|c|c|}
\hline Country & Obs. & $\begin{array}{c}\text { Avg. } \\
\text { yellow } \\
\text { cards / } \\
\text { player- } \\
\text { season }\end{array}$ & Country & Obs. & $\begin{array}{c}\text { Avg. } \\
\text { yellow } \\
\text { cards / } \\
\text { player- } \\
\text { season }\end{array}$ \\
\hline Albania (ALB) & 18 & 2.88 & Macedonia (MKD) & 6 & 4.16 \\
\hline Algeria (DZA) & 6 & 1.50 & Mali (MLI) & 29 & 3.03 \\
\hline Argentina (ARG) & 178 & 2.91 & Mexico (MEX) & 8 & 3.62 \\
\hline Australia (AUS) & 28 & 2.57 & Morocco (MAR) & 26 & 3.15 \\
\hline Austria (AUT) & 6 & 1.66 & Netherlands (NLD) & 118 & 2.06 \\
\hline Belarus (BLR) & 6 & 1.50 & Nigeria (NGA) & 43 & 1.81 \\
\hline Belgium (BEL) & 34 & 1.91 & Northern Ireland (NIR) & 12 & 1.00 \\
\hline Bosnia and Herzegovina (BIH) & 14 & 2.92 & Norway (NOR) & 20 & 1.75 \\
\hline Brazil (BRA) & 277 & 2.44 & Paraguay (PRY) & 14 & 2.42 \\
\hline Bulgaria (BGR) & 20 & 2.55 & Peru (PER) & 13 & 1.38 \\
\hline Cameroon (CMR) & 52 & 2.28 & Poland (POL) & 30 & 1.00 \\
\hline Canada (CAN) & 7 & 3.71 & Portugal (PRT) & 68 & 3.02 \\
\hline Chile (CHL) & 10 & 3.80 & Romania (ROM) & 19 & 1.21 \\
\hline Colombia (COL) & 19 & 4.79 & Russia (RUS) & 8 & 1.75 \\
\hline Congo DR (ZAR) & 10 & 2.50 & Scotland (SCO) & 37 & 2.16 \\
\hline Croatia (HRV) & 48 & 2.37 & Senegal (SEN) & 59 & 2.25 \\
\hline Czech Republic (CZE) & 67 & 2.24 & Serbia (SRB) & 8 & 1.75 \\
\hline Denmark (DNK) & 58 & 1.84 & Serbia and Montenegro (YUG) & 48 & 2.83 \\
\hline Egypt (EGY) & 6 & 1.00 & Sierra Leone & 5 & 2.00 \\
\hline England (GBR) & 402 & 2.17 & Slovak Republic (SVK) & 14 & 0.92 \\
\hline Finland (FIN) & 24 & 1.08 & Slovenia (SVN) & 11 & 1.63 \\
\hline France (FRA) & 721 & 2.48 & South Africa (ZAF) & 15 & 1.06 \\
\hline Georgia (GEO) & 10 & 3.20 & South Korea (KOR) & 5 & 1.00 \\
\hline Germany (DEU) & 424 & 2.00 & Spain (ESP) & 742 & 2.91 \\
\hline Ghana (GHA) & 25 & 2.40 & Sweden (SWE) & 35 & 1.77 \\
\hline Greece (GRC) & 22 & 2.13 & Switzerland (CHE) & 49 & 2.40 \\
\hline Guinea (GIN) & 15 & 2.33 & Togo (TGO) & 8 & 0.75 \\
\hline Hungary (HUN) & 10 & 0.90 & Trinidad and Tobago (TTO) & 5 & 0.20 \\
\hline Iceland (ISL) & 8 & 2.00 & Tunisia (TUN) & 21 & 2.33 \\
\hline Iran (IRN) & 9 & 2.33 & Turkey (TUR) & 24 & 2.25 \\
\hline Ireland (IRL) & 67 & 1.89 & Ukraine (UKR) & 9 & 1.44 \\
\hline Israel (ISR) & 5 & 4.80 & United States (USA) & 30 & 0.96 \\
\hline Italy(ITA) & 730 & 2.81 & Uruguay (URY) & 66 & 2.89 \\
\hline Ivory Coast (CIV) & 49 & 3.26 & Wales (WAL) & 26 & 2.19 \\
\hline Jamaica (JAM) & 9 & 1.77 & & & \\
\hline \multirow[t]{2}{*}{ Japan (JPN) } & 10 & 1.50 & TOTAL countries & 70 & \\
\hline & & & TOTAL observations & 5035 & \\
\hline
\end{tabular}

Notes: The source of this data is the ESPN Soccernet website. We include all countries with at least five player-seasons represented in the leagues for which we have data. 